\title{
Bufavirus, Cosavirus, and Salivirus in Diarrheal Italian Infants
}

\author{
Valentina Daprà ${ }^{a}$ Ilaria Galliano ${ }^{a, b}$ Paola Montanaria ${ }^{a, b}$ Elena Zaniol ${ }^{a, b}$ \\ Cristina Calvi ${ }^{a, b}$ Carla Alliaudi $^{b}$ Massimiliano Bergallo ${ }^{a, b}$ \\ aDepartment of Public Health and Pediatric Sciences, Pediatrics Laboratory, University of Turin, Medical School, \\ Turin, Italy; 'bepartment of Pediatrics, Infectious Diseases Unit, Regina Margherita Children's Hospital, University of \\ Turin, Turin, Italy
}

\section{Keywords}

Bufavirus · Cosavirus · Salivirus · Real-time polymerase chain reaction

\begin{abstract}
Three newly discovered viruses have been recently described in diarrheal patients: Cosavirus (CosV) and Salivirus (SalV), 2 picornaviruses, and bufavirus (BuV), a parvovirus. The detection rate and the role of these viruses remain to be established in acute gastroenteritis (AGE) in diarrheal Italian infants. From November 2016 to November 2017, stool samples were collected from 160 children $<5$ years old suffering from AGE and attending the Children's Hospital in Turin, Italy. During the study period, $1(0.5 \%)$ sample was positive for 1 of the 3 investigated viruses: $0(0 \%)$ CosV, 1 (0.5\%) SalV, and 0 (0\%) BuV, whereas 42 (26.0\%) children were infected with rotavirus and $2(1 \%)$ with adenovirus. No mixed infections involving the 3 viruses were found. Although these viruses are suspected to be responsible for AGE in children, our data showed that this association was uncertain. Therefore, further studies with large cohorts of healthy and diarrheal children will be needed to evaluate their clinical role in AGE.
\end{abstract}

(c) 2021 S. Karger AG, Basel

\section{Introduction}

Diarrhea remains a frequent illness throughout the world and causes the death of almost 6 million children annually, especially in developing countries. Besides welldocumented enteric viruses, the list of viral pathogens causing acute gastroenteritis (AGE) is continuously growing with the emergence of new viruses. No $<3$ new types of virus have been discovered in diarrheal patients these last years: Cosavirus (CosV) and Salivirus (SalV), 2 new genera in the Picornaviridae family since 2013, and bufavirus from the Protoparvovirus genus of the Parvoviridae. $\operatorname{Cos} V$ was first identified in 2008 from children suffering from acute flaccid paralysis but has been later associated with diarrhea. It has been detected in feces from both patients with gastroenteritis and healthy subjects [1]. HCoSV genome is 7,632 base pairs (bp) long and codes for 7 nonstructural proteins $(2 \mathrm{~A}, 2 \mathrm{~B}, 2 \mathrm{C}, 3 \mathrm{~A}, 3 \mathrm{~B}$, $3 \mathrm{C}$, and $3 \mathrm{D}$ ) and 4 structural proteins (VP1, VP2, VP3, and VP4) and has a wide genetic diversity with 6 genetic groups (A-F) and consists of more than 30 genotypes [2].

SalV was first identified in 2009 [3, 4]. SalV has a single-stranded RNA genome of around $7.1 \mathrm{~Kb}$ organized in a typical picornavirus genome. Although this virus is re-

\footnotetext{
Karger"
} 
lated, but distinct, to the Kobuvirus genus, SalV forms a genus that presently includes a single genotype with 2 clusters [5]. Recent molecular epidemiological studies on sporadic gastroenteritis in young children in several countries such as China [6, 7], South Korea [8], Hong Kong [9], India [10, 11], Denmark [12], Germany [13], Brazil [14], Thailand [15], and Tunisia [16] indicate that this virus may be associated with gastroenteritis in humans with a prevalence of $0.1-8.8 \%$. Furthermore, the first SalV outbreak was reported recently among newborn babies in a neonatal hospital unit in Hungary [17].

Bufavirus (BuV) was first discovered in 2012 in fecal samples from children suffering from diarrhea in Burkina Faso, from which it get its name [18]. Thereafter, $\mathrm{BuV}$ was detected in diarrheal stool samples of children from other continents [19-22]. BuV has a single-stranded DNA genome of around $4.9 \mathrm{~Kb}$, which encodes nonstructural protein 1 (NS1) and viral structural protein (VP2). Three genotypes (BuV1, 2, and 3) have been described so far [23], but diversity within the capsid gene suggests the possibility of several other genotypes [18].

Whether these viruses are etiologic agents of human gastroenteritis remains unclear, but knowledge about their distribution and genetic divergence in humans is mounting. In this context, the detection rate and the role of these new viruses in AGE in diarrheal infants remain to be established.

\section{Materials and Methods}

From November 2016 to November 2017, stool samples were collected from 160 children $<5$ years old suffering from AGE and attending the Regina Margherita Children's Hospital in Turin, Italy. The children's median age was 21.2 months (ranging $0.3-60$ months), and the sex ratio was 1 . The study and the data collection procedure were approved by the Ethics and Research Committee of the Città della Salute e della Scienza di Torino institutional Ethics Committee on November 24, 2014, prot. number 116918. Informed consents were obtained verbally from the parents of the study participants and consigned in their clinical records in accordance to the Italian good clinical practices and hospital clinical investigations guidelines. The samples were anonymized before processing.

For each stool sample, nucleic acids were extracted from 400 $\mu \mathrm{L}$ of $12.5 \%$ fecal suspension in PBS on a Maxwell16 system (Promega, Madison, WI, USA) using simply RNA Blood Kit protocol without modification, according to the manufacturer's instructions. RNA/DNA was eluted in a final volume of $50 \mu \mathrm{L}$. For reverse transcription, $5 \mu \mathrm{L}$ of the stored, extracted RNA was added to a reagent mixture consisting of $5 \mathrm{x}$ buffer (Promega), $10 \mathrm{mM}$ dNTPs (Sigma, St. Louis, MO, USA), ImpromII (50 U/ $\mu \mathrm{L})$ (Promega), random primer $(50 \mu \mathrm{M})$ (hexa-deoxyribonucleotide mixture) (Promega), RNase Inhibitor $(20 \mathrm{U} / \mu \mathrm{L})$ (Promega), and distilled water. The total volume of reaction mixture was $50 \mu \mathrm{L}$. RT reaction was carried out at $42^{\circ} \mathrm{C}$ for $60 \mathrm{~min}$, followed by $70^{\circ} \mathrm{C}$ for $15 \mathrm{~min}$.

$\mathrm{CosV}$, SalV, and BuV were screened by real-time RT-PCR using optimized primer and probe kit PP-BioMole073, PP-BioMole074, and PP-BioMole077, respectively (BioMole, Turin, Italy). The PCR amplification was carried out for $2 \mathrm{~min}$ at $50^{\circ} \mathrm{C}, 2 \mathrm{~min}$ at $95^{\circ} \mathrm{C}, 45$ cycles of $15 \mathrm{~s}$ at $95^{\circ} \mathrm{C}, 1 \mathrm{~min}$ at $60^{\circ} \mathrm{C}$ on the $7,500 \mathrm{ABI}$ real-time instrument (Life-Technologies). The adenovirus and rotavirus detection was extracted from the medical record database.

\section{Results}

During the study period, $42(26.0 \%)$ children were infected with rotavirus and $2(1 \%)$ with adenovirus. No mixed infections involving these viruses were found.

All fecal specimens were tested for the presence of $\mathrm{BuV}, \mathrm{SalV}$, and $\mathrm{HCoSV}$ with optimized primer and probe kit. $\mathrm{HCoSV}$ and $\mathrm{BuV}$ were not detected in any of the samples. Real-time PCR detected SalV in $1(0.5 \%)$ case.

\section{Discussion}

With a low detection rate $(0 \%), \mathrm{BuV}$ were not found in Italian stools. These findings are similar to those observed in children from Asia, Europe, or Africa where detection rates range from 0.5 to $4.0 \%$ in patients of all ages [19-22].

Our data showed that the detection rate of CosV in diarrheal children ( $0 \%)$ was lower than that observed in $\mathrm{Tu}$ nisia, China, or Brazil, where they were reported in diarrheal children in $1,2.8$, and $3.6 \%$ of patients $[16,24,25]$, respectively.

Similar to that observed previously in Italy [26], in this study, the detection rate of SalV infections accounted for $0.5 \%$. Although they are globally widespread, SalV seem to circulate more in Asia than in North Africa and Europe. The epidemiological studies in several different geographical areas in the world propose that SalV has a worldwide distribution and it can be the possible etiologic agent of gastroenteritis in humans $[7,27]$. However, there is a low detection rate of SalV with a prevalence of $0.1-8.8 \%$ in patients with gastroenteritis [6-16]. Although SalV infections are reported in different agegroups, the overall most frequent infections have been detected in under 5-year-old children [27, 28]. In contrast, a moderate and high prevalence of SalV has been reported in environmental samples containing raw and treated sewage water and river waters from 15 to $93 \%$ in the USA and Japan and 32.6-71.1\% in Thailand and Bra- 
zil, respectively [29-32]. Regarding highly prevalence identification of SalV in environmental samples, it seems that the possibly transmission route of SalV infections occurs by the fecal-oral route.

A limitation of the study was represented by the limitation data obtained from medical record database. In the studied period, our institution only provides rotavirus and adenovirus in routine screening. The lack of data derived by other gastroenteritis viral agent could be filled introducing norovirus, sapovirus, and other agents in routine procedure.

Although these new viruses are suspected to be responsible for acute gastroenteritis in children, our data showed that this association was uncertain. Therefore, further studies with large cohorts of healthy and diarrheal children will be needed to evaluate their clinical role in acute gastroenteritis.

\section{Statement of Ethics}

The study and the data collection procedure were approved by the Ethics and Research Committee of the Città della Salute e della Scienza di Torino institutional Ethics Committee on November
24, 2014, prot. number 116918. Informed consents were obtained verbally from the parents of the study participants and consigned in their clinical records in accordance to the Italian good clinical practices and hospital clinical investigation guidelines. The samples were anonymized before processing.

\section{Conflict of Interest Statement}

All authors confirm that there are no conflicts of interest.

\section{Funding Sources}

This research was supported by the Institutional Grant RILOBERM18.

\section{Author Contributions}

M.B. and V.D. designed the experiments. P.M. and C.C. developed the experiments. I.G., E.Z., and C.A. prepared the manuscript.

\section{References}

1 Kapoor A, Victoria J, Simmonds P, Slikas E, Chieochansin T, Naeem A, et al. A highly prevalent and genetically diversified picornaviridae genus in South Asian children. Proc Natl Acad Sci USA. 2008;105(51):20482-7.

2 Kapusinszky B, Phan TG, Kapoor A, Delwart E. Genetic diversity of the genus cosavirus in the family picornaviridae: a new species, recombination, and 26 new genotypes. PLoS One. 2012;7(5):e36685.

3 Greninger AL, Runckel C, Chiu CY, Haggerty T, Parsonnet J, Ganem D, et al. The complete genome of klassevirus: a novel picornavirus in pediatric stool. Virol J. 2009;6:82.

4 Holtz LR, Finkbeiner SR, Zhao G, Kirkwood CD, Girones R, Pipas JM, et al. Klassevirus 1, a previously undescribed member of the family Picornaviridae, is globally widespread. Virol J. 2009;6:86.

5 Boros Á, Raáb M, Károly É, Karai A, Kátai A, Bolba N, et al. A cluster of salivirus A1 (picornaviridae) infections in newborn babies with acute gastroenteritis in a neonatal hospital unit in Hungary. Arch Virol. 2016;161(6): 1671-7.

6 Shan T, Wang C, Cui L, Yu Y, Delwart E, Zhao $\mathrm{W}$, et al. Picornavirus salivirus/klassevirus in children with diarrhea, China. Emerging Infect Dis. 2010;16(8):1303-5.
7 Yu JM, Ao YY, Liu N, Li LL, Duan ZJ. Salivirus in children and its association with childhood acute gastroenteritis: a paired case-control study. PLoS One. 2015;10(7):e0130977.

8 Han $\mathrm{TH}$, Kim $\mathrm{CH}$, Chung JY, Park SH, Hwang ES. Klassevirus infection in children, South Korea. Emerging Infect Dis. 2010; 16(10):1623-5.

9 Yip CC, Lo KL, Que TL, Lee RA, Chan KH, Yuen KY, et al. Epidemiology of human parechovirus, aichi virus and salivirus in fecal samples from hospitalized children with gastroenteritis in Hong Kong. Virol J. 2014;11:182.

10 Itta KC, Patil T, Kalal S, Ghargi KV, Roy S Salivirus in children with diarrhoea, western India. Int J Infect Dis. 2016;52:14-5.

11 Lasure N, Gopalkrishna V. Clinico-epidemiology and genetic diversity of Salivirus in acute gastroenteritis cases from Pune, Western India: 2007-2011. Infect Genet Evol. 2016;44:425-30.

12 Nielsen AC, Gyhrs ML, Nielsen LP, Pedersen C, Böttiger B. Gastroenteritis and the novel picornaviruses aichi virus, cosavirus, saffold virus, and salivirus in young children. J Clin Virol. 2013;57(3):239-42.

13 Aldabbagh S, Eckerle I, Müller A, Delwart EL, Eis-Hübinger AM. Salivirus type 1 and type 2 in patients with acute gastroenteritis, Germany. J Clin Virol. 2015;72:16-9.
14 Santos N, Mendes GS, Silva RC, Pena GA, Rojas M, Amorim AR, et al. Salivirus and aichivirus $\mathrm{A}$ infections in children with gastroenteritis in Brazil. Clin Microbiol Infect. 2015; 21(8):799-3.

15 Kumthip K, Khamrin P, Yodmeeklin A, Maneekarn N. Salivirus infection in children with diarrhea, Thailand. Arch Virol. 2017; 162:2839-41.

16 Ayouni S, Estienney M, Hammami S, Neji Guediche M, Pothier P, Aouni M, et al. Cosavirus, salivirus and bufavirus in diarrheal $\mathrm{Tu}$ nisian infants. PLoS One. 2016;11(9): e0162255.

17 Boros Á, Raáb M, Károly É, Karai A, Kátai A, Bolba N, et al. A cluster of salivirus A1 (picornaviridae) infections in newborn babies with acute gastroenteritis in a neonatal hospital unit in Hungary. Arch Virol. 2016;161(6): 1671-7.

18 Phan TG, Vo NP, Bonkoungou IJ, Kapoor A, Barro N, O'Ryan M, et al. Acute diarrhea in West African children: diverse enteric viruses and a novel parvovirus genus. J Virol. 2012; 86(20):11024-30.

19 Altay A, Yahiro T, Bozdayi G, Matsumoto T, Sahin F, Ozkan S, et al. Bufavirus genotype 3 in Turkish children with severe diarrhoea. Clin Microbiol Infect. 2015;21(10):965. 
20 Chieochansin T, Vutithanachot V, Theamboonlers A, Poovorawan Y. Bufavirus in fecal specimens of patients with and without diarrhea in Thailand. Arch Virol. 2015;160(7): 1781-4.

21 Huang DD, Wang W, Lu QB, Zhao J, Guo CT, Wang HY, et al. Identification of bufavirus-1 and bufavirus- 3 in feces of patients with acute diarrhea, China. Sci Rep. 2015;5:13272.

22 Smits SL, Schapendonk CM, van Beek J, Vennema H, Schürch AC, Schipper D, et al. New viruses in idiopathic human diarrhea cases, the Netherlands. Emerging Infect Dis. 2014;20(7):1218-22.

23 Yahiro T, Wangchuk S, Tshering K, Bandhari $\mathrm{P}$, Zangmo S, Dorji T, et al. Novel human bufavirus genotype 3 in children with severe diarrhea, Bhutan. Emerging Infect Dis. 2014; 20(6):1037-9.
24 Dai XQ, Hua XG, Shan TL, Delwart E, Zhao $\mathrm{W}$. Human cosavirus infections in children in China. J Clin Virol. 2010;48(3):228-9.

25 Stocker A, Souza BF, Ribeiro TC, Netto EM, Araujo LO, Correa JI, et al. Cosavirus infection in persons with and without gastroenteritis, Brazil. Emerg Infect Dis. 2012;18(4): 656-9.

26 Bergallo M, Daprà V, Rassu M, Bonamin S, Cuccu R, Calvi C, et al. Prevalence and clinical profile of human salivirus in children with acute gastroenteritis in Northern Italy, 20142015. Intervirology. 2018;61(1):49-52.

27 Reuter G, Pankovics P, Boros Á. Saliviruses the first knowledge about a newly discovered human picornavirus. Rev Med Virol. 2017; 27(1):e1904.

28 Richman DD, Whitley RJ, Hayden FG. Clinical virology. Washington, DC: American Society for Microbiology Press; 2010. Vol. 15; p. 1692.
29 Haramoto E, Otagiri M. Prevalence and genetic diversity of klassevirus in wastewater in Japan. Food Environ Virol. 2013;5(1):46-51.

30 Kitajima M, Iker BC, Rachmadi AT, Haramoto E, Gerba CP. Quantification and genetic analysis of salivirus/klassevirus in wastewater in Arizona, USA. Food Environ Virol. 2014; 6(3):213-6.

31 Badru S, Khamrin P, Kumthip K, Yodmeeklin A, Surajinda S, Supadej K, et al. Molecular detection and genetic characterization of Salivirus in environmental water in Thailand. Infect Genet Evol. 2018;65:352-6.

32 Silva-Sales M, Seglia Caldas M, Monassa Fioretti J, Simoes Rocha M, Machado Fumian T, Pereira Miagostovich M. Detection of Salivirus in raw sewage samples in Rio de Janeiro, Brazil. J Trop Pathol. 2020;49. 